University of Nebraska - Lincoln

DigitalCommons@University of Nebraska - Lincoln

4-19-2007

\title{
Adaptation and mitigation strategies in agriculture: an analysis of potential synergies
}

Cynthia Rosenzweig

NASA Goddard Institute for Space Studies, cynthia.rosenzweig@nasa.gov

Francesco Nicola Tubiello

Columbia University

Follow this and additional works at: https://digitalcommons.unl.edu/nasapub

Part of the Physical Sciences and Mathematics Commons

Rosenzweig, Cynthia and Tubiello, Francesco Nicola, "Adaptation and mitigation strategies in agriculture: an analysis of potential synergies" (2007). NASA Publications. 25.

https://digitalcommons.unl.edu/nasapub/25

This Article is brought to you for free and open access by the National Aeronautics and Space Administration at DigitalCommons@University of Nebraska - Lincoln. It has been accepted for inclusion in NASA Publications by an authorized administrator of DigitalCommons@University of Nebraska - Lincoln. 


\title{
Adaptation and mitigation strategies in agriculture: an analysis of potential synergies
}

\author{
Cynthia Rosenzweig · Francesco Nicola Tubiello
}

Received: 8 May 2006/Accepted: 23 May 2006/Published online: 19 April 2007

(C) Springer Science+Business Media B.V. 2007

This article is a U.S. government work, and is not subject to copyright in the United States.

\begin{abstract}
As climate changes due to rising concentrations of greenhouse gases in the atmosphere, agriculture will be one of the key human activities affected. Projections show that while overall global food production in the coming decades may keep pace with the food requirements of a growing world population, climate change might worsen existing regional disparities because it will reduce crop yields mostly in lands located at lower latitudes where many developing countries are situated. Strategies to enhance local adaptation capacity are therefore needed to minimize climatic impacts and to maintain regional stability of food production. At the same time, agriculture as a sector offers several opportunities to mitigate the portion of global greenhouse gas emissions that are directly dependent upon land use, land-use change, and land-management techniques. This paper reviews issues of agriculture and climate change, with special attention to adaptation and mitigation. Specifically, as adaptation and mitigation strategies in agriculture are implemented to alleviate the potential negative effects of climate change, key synergies need to be identified, as mitigation practices may compete with modifications to local agricultural practices aimed at maintaining production and income. Under future climate and socio-economic pressures, land managers and farmers will be faced with challenges in regard to selecting those mitigation and adaptation strategies that together meet food, fiber and climate policy requirements.
\end{abstract}

Keywords Adaptation - Agriculture - Climate change impacts · Mitigation · Regional disparities $\cdot$ Synergies $\cdot$ Tradeoffs

C. Rosenzweig $(\bowtie)$

NASA Goddard Institute for Space Studies, New York, NY, USA

e-mail: crosenzweig@giss.nasa.gov

C. Rosenzweig · F. N. Tubiello

Columbia University, New York, NY, USA 


\section{Introduction}

Climate change will affect the productivity of crop species and their geographic distribution. Major contributing factors will include increasing atmospheric carbon dioxide, rising temperature and a modified frequency of extreme events, possibly leading to more drought and floods. These changes will in turn alter the availability of water resources, productivity of grazing lands and livestock, and the distribution of agricultural pests and diseases. Overall effects on cropping systems and farm activities will vary regionally. Importantly, they will also depend on the specific management systems in use and their adaptive capacities. Several studies suggest that recent warming trends in some regions may already have discernible effects on agricultural systems (e.g., Nicholls 1997; Peng et al. 2004).

The Intergovernmental Panel on Climate Change (IPCC 2000; 2001a) has attributed the observed warming over the last century to anthropogenic forcing, i.e., the human-driven emissions of greenhouse gases, chiefly carbon dioxide $\left(\mathrm{CO}_{2}\right)$, methane $\left(\mathrm{CH}_{4}\right)$, and nitrous oxide $\left(\mathrm{N}_{2} \mathrm{O}\right)$ (IPCC 2001a). Currently, the magnitude of observed warming is about $0.6^{\circ} \mathrm{C}$ over the last century, and mean global temperatures in the Northern hemisphere are higher this century than they have been in the last 1,000 years (IPCC 2001a).

The ultimate significance of the climate change issue is related to its global reach, affecting sectors and regions throughout the world in complex and interactive ways. In this paper, we summarize recent studies projecting how climate change will affect agriculture in the future, and focus on the potential roles of adaptation and mitigation strategies, and their interactions, in responding to climate change.

\section{Climate change and agriculture}

A changing climate will affect agro-ecosystems in heterogeneous ways, with either benefits or negative consequences dominating in different agricultural regions (Fig. 1). However, the factors that prevail regionally may change over time, as gradual and possibly abrupt climate changes develop in this century. Rising atmospheric $\mathrm{CO}_{2}$ concentration, higher temperature, changing patterns of precipitation, and altered frequencies of extreme events will have significant effects on crop production, with associated consequences for water resources and pest/disease distributions.
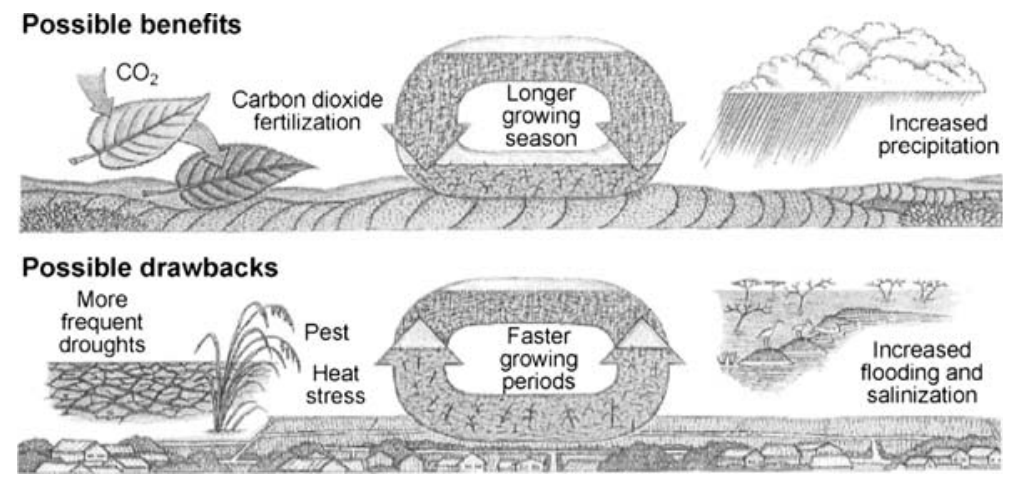

Fig. 1 Agro-ecosystem processes and a changing climate (from: Bongaarts 1994) 


\subsection{Atmospheric carbon dioxide concentration}

Many experiments show that crop yields increase on average by $\sim 30 \%$ for a doubling of $\mathrm{CO}_{2}$ concentration (Acock and Allen 1985; Cure and Acock 1986; Kimball 1983; Poorter 1993; Hsiao and Jackson 1999). Recent free-air $\mathrm{CO}_{2}$ enrichment (FACE) experiments in well-managed fields confirm these positive results (Hendrey et al. 1993; Kimball et al. 2002). Importantly, crop responses to elevated $\mathrm{CO}_{2}$ have been shown to be modulated by environmental and management factors. For instance, relative crop yield response to elevated $\mathrm{CO}_{2}$, compared to ambient $\mathrm{CO}_{2}$ levels, is greater in rain-fed than in irrigated crops, due to a combination of increased water-use efficiency and root water-uptake capacity (Tubiello and Ewert 2002). High-temperature and salinity stress may also increase relative crop response, at least in the short term. Conversely, low fertilizer $\mathrm{N}$ applications tend to depress crop responses to elevated $\mathrm{CO}_{2}$ (Kimball and Idso 1983; Kimball et al. 2002).

It remains uncertain whether many of the effects of $\mathrm{CO}_{2}$ enrichment observed in controlled and FACE environments will prevail in farmers' fields in the future. Under these more typical conditions, many existing limiting factors—such as soil and water quality, weed-crop competition, weed and pest interactions-as well as their unknown evolution under elevated $\mathrm{CO}_{2}$ and a changing climate might suppress the yield gains seen in current experiments (e.g., Rosenzweig and Hillel 1998; Tubiello and Ewert 2002).

\subsection{Temperature}

Agricultural production may already have been affected by rising temperatures in recent decades. For instance, Nicholls (1997) suggested that temperature trends in Australia were responsible for $30-50 \%$ of observed recent gains in wheat yields, with increases in minimum temperatures and a related decrease in frost frequency the dominant influence. Recently observed temperature increases may be extending crop-growing seasons in other regions. Chmielewski et al. (2004) found that in Germany, for the period 1961-1990, the beginning of the growing season advanced by 2.3 days per decade, following increases in mean annual air temperature of $0.36^{\circ} \mathrm{C}$ per decade. Over the same period, warmer temperatures advanced the beginning of stem elongation in rye by 2.9 days per decade; the beginning of cherry tree blossom by 2 days per decade; and the beginning of apple tree blossom by 2.2 days per decade.

Rising temperatures may also be affecting yields in tropical regions. Peng et al. (2004), analyzing 1979-2002 data from The Philippines, conclude that rice grain yields have declined by about $15 \%$ for each $1^{\circ} \mathrm{C}$ increase in growing-season mean temperature.

\subsection{Climate variability, extreme events, and sea-level rise}

Climate change may be characterized by an increase in climate variability (IPCC 2001a). This may heighten the risks of crop failures, often connected to specific extreme events during critical crop phases, such as heat waves or late frosts during flowering. In addition, increases in temperature and precipitation variability will put pressure on crops grown on their marginal climate ranges: for instance, increases in temperature variability in southern wheat-growing areas may limit yields through lack of cold hardening and increased winterkill. 
Precipitation extremes (i.e., droughts or floods) are also detrimental to crop productivity. Higher heavy precipitation and flooding regimes could increase crop damage in some areas, due to soil water-logging, physical plant damage, and pest infestation (Rosenzweig et al. 2002a, b). At the opposite extreme, greater drought frequency and increased evaporative demands may increase the need for irrigation in specific regions, further straining competition for water with other sectors (Rosenzweig et al. 2004). In regions lacking additional water resources, entire cropping systems may go out of production.

In coastal agricultural regions, sea-level rise and associated saltwater intrusion and storm-surge flooding can harm crops through diminished soil aeration, salinization, and direct damage. This is likely to be most serious in countries such as Egypt and Bangladesh, with major crop-growing areas in low-lying coastal regions.

\subsection{Agricultural pests}

Under climate change, pests associated with specific crops may become more active (Coakley et al. 1999; IPCC 1996). Increased use of agricultural chemicals might become necessary, with consequent health, ecological, and economic costs (Rosenzweig et al. 2002a, b; Chen and McCarl 2001).

Higher temperatures may increase the growth of some weed species and extend their geographic range towards higher latitudes (Dahlsten and Garcia 1989; Sutherst 1990). In addition, warmer temperatures may speed development rates of some insect species; resulting in shortened times between generations and improved capacity for over-wintering at northern latitudes. Some insects populations may further become established and thrive earlier in the growing season, during more vulnerable crop stages.

Current crop-pest interactions may change in response to elevated $\mathrm{CO}_{2}$. For instance, due to differential responses of weeds and crops to $\mathrm{CO}_{2}$, some $\mathrm{C}_{3}$ weeds may become more invasive (Patterson 1993). Elevated $\mathrm{CO}_{2}$ may also indirectly modify insect-crop relations, via an increase in the $\mathrm{C}: \mathrm{N}$ ratio in crop leaves, which renders them less nutritious per unit mass. This would stimulate increased feeding by insects, leading to more plant damage (Lincoln et al. 1984; Salt et al. 1995).

\section{Global and regional predictions}

Despite uncertainties about the rate and magnitude of climate change, recent assessment studies have consistently shown that agricultural production systems in the mid and high latitudes are likely to benefit in the near term (approximately to mid-century), while production systems in the low-latitudes may decline over the coming few decades. Since most of the developing countries are located in lower-latitude regions, increased divergence in climate vulnerability between these groups of nations is expected (IPCC WG II 2001b). The combination of greater climate vulnerability and lower adaptive capacity may create critical, additional challenges to developing countries as they confront global warming in the coming decades. As shown in Table 1, these projections are confirmed by simulation studies analyzing the consequences of global and regional climate impacts on world food supply, in the context of concomitant socio-economic development over this century (Parry et al. 2004; Rosenzweig and Parry 1994; IPCC 2001a, b, c).

If greenhouse gas emissions are not abated, crop production in more developed midand high-latitude regions is also likely to decline towards the end of this century (Fig. 2). 
Table 1 Aggregated developing-developed country differences (per cent) in average crop yield changes from baseline for the Hadley HadCM2 and HadCM3 climate change scenarios (Parry et al. 2004)

\begin{tabular}{|c|c|c|c|c|c|c|c|c|c|}
\hline \multirow[t]{2}{*}{ Scenario } & \multicolumn{7}{|c|}{ HadCM3-2080s } & \multicolumn{2}{|c|}{$\mathrm{HadCM} 2-2080 \mathrm{~s}$} \\
\hline & A1F & A2a & $\mathrm{A} 2 \mathrm{~b}$ & $\mathrm{~A} 2 \mathrm{c}$ & B1a & B2a & $\mathrm{B} 2 \mathrm{~b}$ & S550 & S750 \\
\hline $\mathrm{CO}_{2}(\mathrm{ppm})$ & 810 & 709 & 709 & 709 & 527 & 561 & 561 & 498 & 577 \\
\hline World & -5 & 0 & 0 & -1 & -3 & -1 & -2 & -1 & 1 \\
\hline Developed & 3 & 8 & 6 & 7 & 3 & 6 & 5 & 5 & 7 \\
\hline $\begin{array}{l}\text { Developing } \\
\text { Difference (\%) }\end{array}$ & -7 & -2 & -2 & -3 & -4 & -3 & -5 & -2 & -1 \\
\hline Developed-developing & 10.4 & 9.8 & 8.4 & 10.2 & 7.0 & 8.7 & 9.3 & 6.6 & 7.7 \\
\hline
\end{tabular}

This is because the detrimental effects of increased heat and water stress on crop growth will continue to progress as temperatures rise, while the beneficial effects of $\mathrm{CO}_{2}$ on crop yield will likely level out as $\mathrm{CO}_{2}$ increases.

\section{Response strategies}

\subsection{Adaptation strategies}

Regardless of what local, regional and global actions are taken and which policy instruments are adopted to slow anthropogenic emissions of greenhouse gases and thus to reduce the magnitude of climate change, cumulative past emissions have already committed the planet to a certain degree of climate change and associated impacts over the coming decades. Climate actions taken today will determine how such changes will further evolve in the second half of this century. Recent observations of increased frequency of climate extremes worldwide, as well as shifts in eco-zones, might be an indication of globalwarming-related changes already under way (e.g., IPCC 2001a, b, c; Milly et al. 2002; Root et al. 2003). Sectoral adaptation is thus very likely in the future and integral to the study of climate change impacts on agriculture (IPCC 2001a, b, c; Smit and Skinner 2002; Smith et al. 2003).

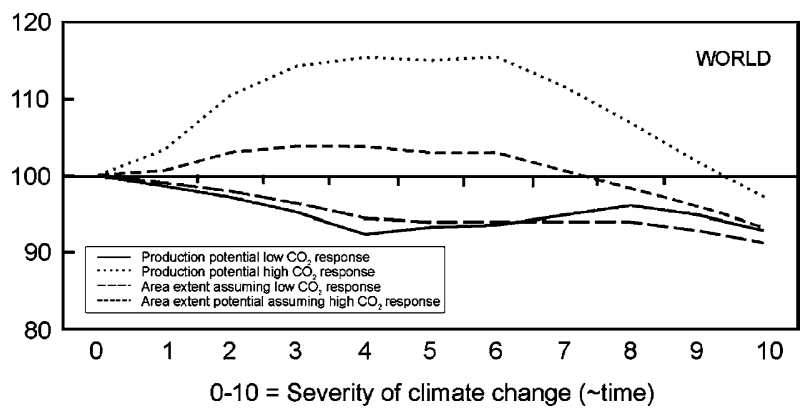

Fig. 2 Generalized projection of world cereal production potential and areal extent under low and high $\mathrm{CO}_{2}$ responses for increasing severity of climate change (data from Fischer et al. 2001) 
The key task at hand is to integrate findings and insights from the physical and social sciences with local knowledge from farmers and land managers, in order to provide guidance to decision-makers so as to promote robust sectoral strategies and appropriate international cooperation. The aim is one of selecting strategies that, over a range of likely future climate and socio-economic scenarios, minimize the potential negative impacts of climate change while maximizing opportunities for adjustment.

Adaptation in agriculture is the norm rather than the exception. In addition to changes driven by several socio-economic factors (chiefly market conditions and policy frameworks), farmers always had to adapt to the vagaries of weather, on weekly, seasonal, annual and longer timescales. The real issue in the coming decades will be the rate and nature of climate change compared to the adaptation capacity of farmers. If future changes are relatively smooth, farmers may successfully adapt to changing climates in the coming decades by applying a variety of agronomic techniques that already work well under current climates, such as adjusting the timing of planting and harvesting operations, substituting cultivars, and-where necessary-modifying or changing altogether their cropping systems.

Adaptation strategies will vary with agricultural systems, location, and scenarios of climate change considered. For cereals, different adaptation strategies are needed for fallsown crops, such as winter wheat and barley, compared to spring crops, such as maize and spring wheat. For example, a crop simulation study done as part of the U.S. National Assessment (Tubiello et al. 2002) considered simple farm-level techniques, available today, such as early planting - a realistic adaptation to climate change at many northern agricultural sites - and the use of cultivars better adapted to warmer climates compared to those currently grown at specific locations.

Early planting was simulated for spring crops to take advantage of changes in planting windows caused by advances of last-frost dates, as well as to provide for heat and drought stress avoidance in the late summer months. Growth and yield of better heat-adapted cultivars were simulated for winter crops, such as winter wheat and barley, by testing performance of cultivars with increased length of the grain-filling period. Under warmer climates, crops would tend to mature faster, resulting in less time available for carbohydrate accumulation and grain production. By substituting current cultivars with ones requiring longer time to mature, yield potential under climate change may be restored to levels typical of current conditions. An additional adaptation strategy for winter-sown cereals is the planting of cultivars having a reduced need for vernalization, i.e., the requirements for set periods of cold temperatures during the vegetative stage of the crop to induce bud formation in spring.

Responses to specific adaptation strategies for given cropping systems can still vary considerably, as a function of location and climate scenario (Fig. 3). For instance, adapting winter cereal production by using longer-maturing cultivars requires enough precipitation over the extended growing season to sustain grain filling. If the particular climate scenario considered consists of both warmer and drier conditions, such an adaptation strategy will likely not work. Additionally, such a strategy might not work at southern sites, regardless of the climate scenario considered, because farmers there already plant cultivars having low vernalization requirements and maturity times in the upper range of those available. In such cases, effective adaptation might not be possible without further breeding programs, a process that typically takes a decade or longer before newly adapted cultivars can be distributed to farmers. By the same token, Reilly et al. (2003) projected that early planting could be a successful strategy for maize and spring wheat in the US Midwest, but not for potato. 

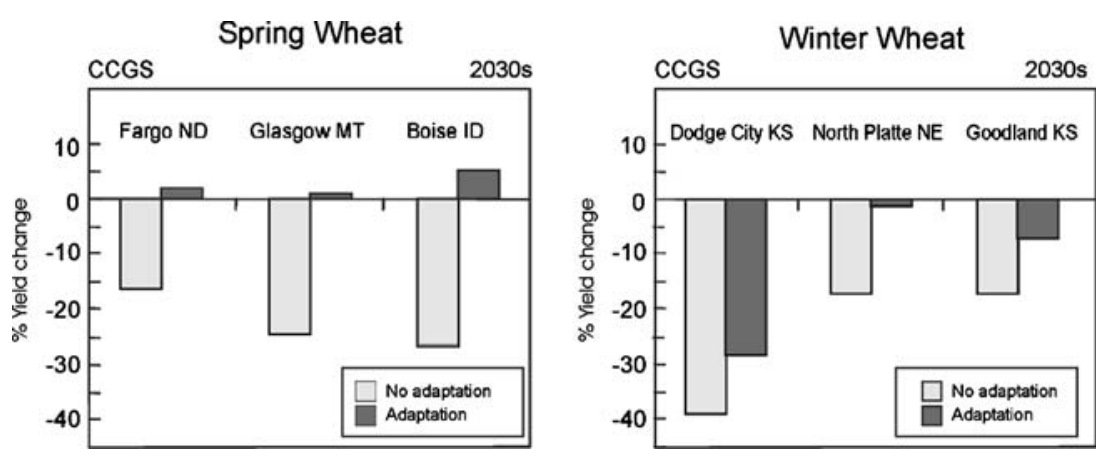

Fig. 3 Percent yield changes with and without adaptation under the Canadian. Climate Centre climate change scenario in the 2030s: (left) spring wheat, with change of planting date; (right) winter wheat with change of cultivar (Tubiello et al. 2002)

In addition to changing planting strategies and cultivar type, land management systems could be adapted to new climate conditions. Shifts from rainfed to irrigated agriculture is the simplest such solution, although issues of water availability, cost, and competition from other sectors need to be considered (i.e., Reilly et al. 2003; Tubiello et al. 2002; Rosenzweig et al. 2004). At higher levels of adaptation, cropping systems and crop types could be changed altogether in addition to field management adjustments (i.e., Reilly et al. 2003), or cultivation areas could shift geographically, following the creation of new agricultural zonations determined by a changing climate (e.g., Fischer et al. 2001).

We note that our discussion on modeling adaptation is based primarily on agronomic techniques that are either readily implemented by farmers today, or are likely to be readily available in the coming decades, based on current knowledge. One advantage of this approach is its specificity, since it can be easily communicated to and discussed with stakeholders. The efficacy of such agronomic adaptation strategies under climate change in a variety of production systems for given regions is easily tested within dynamic crop models (e.g., Rosenzweig et al. 1995; Tubiello et al. 2002).

On the other hand, such an approach may be too farm-specific for assessment of more aggregated levels of adaptation, involving, for example, regional planning for large-scale changes in management and cropping systems that include sectoral competition for land and water use or other market pressures. For these kinds of analyses, several authors have used more economic-based approaches, allowing for qualitative-quantitative assessments of higher levels of adaptation potentials, albeit with less agronomic detail (e.g., Polsky 2004; Adams et al. 1999; Easterling et al. 1993; Mendelsohn et al. 1994). These studies tend to indicate small overall positive impacts for global agricultural economic indicators across scenarios and models in the first half of this century, for climate changes at the global scale of up to about $3^{\circ} \mathrm{C}$, and negative impacts above that degree of warming (see e.g., Hitz and Smith 2004).

So far we have discussed adaptation strategies that might provide responses to climate changes associated with smooth changes in mean variables, such as temperature and precipitation regimes. What about climate variability? There are strong indications that climate change will also bring about pronounced changes in climate variability (IPCC 2001a, b, c). Several studies have indicated that specific scenarios with mean warmer and wetter conditions might be associated with increased frequency of heavy precipitation events (i.e., Milly et al. 2002), with potential implications for increased crop losses. For 
example, Rosenzweig et al. (2002a, b) computed that agricultural losses in the U.S. due to heavy precipitation and excess soil moisture could double by 2030.

As opposed to adaptation to changes in mean conditions, which require adjustments in agronomic techniques (e.g., planting calendars, cultivar types, input amounts), adaptation to future changes - likely an increase - in climate variability may require an attention to stability and resilience of production, rather than to improving its absolute levels. Crop management and cropping systems have evolved to provide farmers with stability of production and thus steady income in the face of uncertain weather. The coefficient of variation $(\mathrm{CV})$ of yield in given areas may be used as a measure of system stability, providing insight into superior cropping techniques at given sites. For example, continuous winter wheat in Nebraska can have high CVs, over 50\%, with high risk of complete crop failure (as high as one in 5-10 years). Fallow practices that leave agricultural fields to rest and accumulate moisture every other year, produce lower CVs (around 15\%) and higher long-term yields because of reductions in crop-failure probabilities. Cropping rotations, integrated pest management, soil conservation and fallow techniques are all examples of management practices that contribute to stability of farm production and income.

It is important to note that farming systems better adapted to local conditions are not fully immune to risk, even under current conditions (witness the recurrent effects of droughts and floods on various agricultural regions around the world). Hence it seems unreasonable to expect perfect adaptation in the future to changing climate conditions. Some adaptations will likely be successful (e.g., change in planting dates to avoid heat stress), while other attempted adaptations (e.g., changing varieties and breeds, altered crop rotations, development of new agricultural areas) may not always be effective in avoiding the negative effects of droughts or floods on crop and livestock production. Importantly, there are additional dimensions to adaptation, related to social and cultural aspects, that might either favor or hinder adoption of new techniques by farmers, depending on community dynamics (Smith et al. 2003; Smit and Skinner 2002).

\subsection{Mitigation strategies}

While agriculture stands to be greatly affected by projected climate change, it also is, and has been historically, a major source of greenhouse gases to the atmosphere, thus itself contributing to climate change, possibly even from its inception. Clearing and management of land for food and livestock production over the past century was responsible for cumulative carbon emissions of about 150 GT C, compared to 300 GT C from fossil fuels (LULUCF 2000). At present, agriculture and associated land use changes emit about a quarter of the carbon dioxide (through deforestation and soil organic carbon depletion, machine and fertilizer use), half of the methane (via livestock and rice cultivation), and three-fourths of the nitrous oxide (through fertilizer applications and manure management) annually released into the atmosphere by human activities.

Modifying current management of agricultural systems could therefore greatly help to mitigate global anthropogenic emissions. Many see such activities in the coming decades as new forms of environmental services to be provided to society by farmers, who in turn could additionally increase their income by selling carbon-emission credits to other carbon-emitting sectors.

We focus this discussion on the agricultural carbon cycle, offering several entry points for mitigation of greenhouse gas accumulation in the atmosphere. To this end, possible mitigation approaches in agriculture concentrate on either (or both) of two key 
components: (1) Sequestration of atmospheric $\mathrm{C}$ in agricultural soils, resulting in increased soil organic carbon (SOC) pools; and (2) Reduction of greenhouse gas emissions to the atmosphere from agricultural operations. An important difference among the two options above is that soil carbon sequestration is ultimately finite (Lal et al. 1999): positive manipulations in soil management will tend to increase the equilibrium soil carbon pool by increasing $\mathrm{C}$ inputs into the soil or by slowing decay rates of soil organic matter, but SOC accumulation will not proceed above the resulting new storage point. By contrast, management changes that reduce carbon fluxes from agricultural operations can last indefinitely, as long as the new management system is sustainable in both energy and ecological terms (Schlesinger 1999).

\subsubsection{Carbon sequestration}

Of the $150 \mathrm{GT} C$ that were lost in the last century due to land conversion to agriculture and subsequent production, about two thirds were lost due to deforestation and one-third, roughly $50 \mathrm{GTC}$, due to cultivation of current agricultural soils and exports as food products (LULUCF 2000). The latter figure thus represents the maximum theoretical amount of carbon that could be restored in agricultural soils. In practice, as long as 40-50\% of total above-ground grain or fruit production is exported as food to non-agricultural areas, the actual carbon amount that can be restored in agricultural soils is much lower. Efforts to improve soil quality and raise SOC levels can be grouped into two sets of practices: crop management and conservation tillage. Both practices evolved as means to enhance sustainability and resilience of agricultural systems, rather than with SOC sequestration in mind. They include so-called "best practice", agricultural techniques, such as use of cover crops and/or nitrogen fixers in rotation cycles; judicious use of fertilizers and organic amendments; soil water management improvements to irrigation and drainage; and improved varieties with high biomass production. Tables 2 and 3 summarize potentials for C-sequestration for a variety of agronomic field techniques.

By combining this information with current and future agricultural land use, including levels of technology projected by IPCC and FAO (LULUCF 2000; Fischer et al. 2001), we can make a first-order estimate of total future contributions to soil carbon storage from agricultural practices over existing agricultural and marginal lands. Table 4 shows that,

Table 2 Estimated carbon sequestration rates for different "good practice" management practices

\begin{tabular}{llll}
\hline Practice & Country/region & $\mathrm{C}$ gain $\left(\mathrm{T} \mathrm{C} \mathrm{ha}^{-1} \mathrm{yr}^{-1}\right)$ & Time (years) \\
\hline Improved crop production and erosion control & Global & $0.05-0.76$ & 25 \\
Partial elimination of bare fallow & Canada & $0.17-0.76$ & $15-25$ \\
& USA & $0.25-0.37$ & 8 \\
Irrigation & USA & $0.1-0.3$ & \\
Fertilization & USA & $0.1-0.3$ & 10 \\
Yield increase, reduced bare fallow & China & 0.02 & $50-100$ \\
Amendments & Europe & $0.2-1.0$ & 37 \\
Forages in rotation & Norway & 0.3 & 100 \\
Ley-arable farming & Europe & 0.54 & \\
\hline
\end{tabular}

Source: LULUCF (2000), IPCC (2000a) 
Table 3 Estimated carbon sequestration rates under reduced or no tillage practices, as reported in various countries

Source: LULUCF (2000), IPCC (2000a)

Table 4 Estimated carbon sequestration over the next 40 years, as a function of land use management of existing cultivated and marginal land. Data elaborated from regional and temporal data in LULUCF (2000), IPCC (2000)

\begin{tabular}{lll}
\hline Country/region & $\mathrm{C}$ gain $\left(\mathrm{T} \mathrm{C} \mathrm{ha}^{-1} \mathrm{yr}^{-1}\right)$ & Time (years) \\
\hline Global & $0.1-1.3$ & 25 \\
UK & 0.15 & $5-10$ \\
Australia & 0.3 & $10-13$ \\
USA & 0.3 & $6-20$ \\
Canada & 0.2 & $8-12$ \\
USA and Canada & $0.2-0.4$ & 20 \\
Europe & 0.34 & $50-100$ \\
Southern USA & 0.5 & 10 \\
\hline
\end{tabular}

Sector Total Gt C sequestered

"Best Practice", Crop management

Agroforesty improvements

Cropland conversion to agroforesty

Cropland conversion to grassland

Total arable land
8

1.6

19.5

2.4

31.5

over the next 40 years, best practice and conservation tillage alone could store about 8 GT C in agricultural soils. Larger amounts could be sequestered over the same period by increasing $\mathrm{C}$ inputs into land, for instance by establishing agro-forestry practices in marginal lands (20 GT C), or by reducing disturbance, such as by conversion of excess agricultural land to grassland (3 GT C). The total gain from multiple mitigation approaches over existing agricultural land would thus be roughly $10 \mathrm{GT} \mathrm{C}$ (and up to $30 \mathrm{GT} C$ with the inclusion of marginal land conversion for agro-forestry), an amount lower than the 50 GT C lost historically.

An important caveat to the implementation of best practice and reduced tillage agriculture as a means to enhance SOC sequestration is that $\mathrm{C}$ emitted from the manufacture and use of additional agricultural inputs may negate all or part of the increased $\mathrm{C}$ sequestered by soils (Schlesinger 1999). Under current practices, the fossil fuel that powers the machinery to sow, irrigate, harvest, and dry crops worldwide, and including fertilizer manufacture, is already responsible for atmospheric emissions of about 150$200 \mathrm{MT} \mathrm{C} \mathrm{yr}^{-1}$. Given that total cropland covers about $1.5 \mathrm{G}$ ha of global ice-free land, this figure corresponds to a world average emission rate of $100-130 \mathrm{~kg} \mathrm{C} \mathrm{ha}^{-1} \mathrm{yr}^{-1}$.

In order to assess fully the net $\mathrm{C}$ effects of a mitigation practice, it is necessary to analyze the full $\mathrm{C}$ cycle of a given agricultural system. For example, a recent study (West and Marland 2002) analyzed the full $\mathrm{C}$ cycle for intensive agriculture in the US Midwest (corn, wheat, and soybean rotation systems) and found that reduced-tillage agriculture was superior to conventional tillage (CT), not only in terms of its direct benefits ( $\mathrm{C}$ stored in soil of $330 \mathrm{~kg} \mathrm{C} \mathrm{ha}^{-1} \mathrm{yr}^{-1}$ compared to zero in CT), but also in terms of indirect effects, resulting in reduced $\mathrm{C}$ emissions from reduced requirements for field operations and inputs (137 kg C ha $\mathrm{kg}^{-1}$ in reduced tillage versus $178 \mathrm{~kg} \mathrm{C} \mathrm{ha}^{-1} \mathrm{yr}^{-1}$ in CT). The latter indirect reductions were accomplished in spite of increased input use (mainly pesticides and herbicides), because machinery and labor for soil preparation were much lower in the reduced-tillage systems. 


\subsubsection{On-farm reduction of greenhouse gas emissions}

In general, the direct benefits of carbon sequestration in reduced tillage systems are limited in time, typically 20-40 years, while those arising from reduced $\mathrm{C}$ emissions will last as long as the relative management changes are maintained. Therefore, even when such flux reductions appear small compared to total anthropogenic emissions, they may contribute substantially to mitigate sectoral emissions. In the case of US agriculture for example, the estimates by West and Marland (2002) suggest that reduced tillage practices could contribute to making US agriculture 'carbon neutral' over the next 40 years. If they were extended to the $200 \mathrm{M}$ ha of total US cropland, they could sequester and/or reduce overall carbon emissions in agriculture by about 40-50 $\mathrm{MT} \mathrm{C} \mathrm{yr}^{-1}$. These estimates, in agreement with previous studies (i.e., Lal et al. 1999; Sperow et al. 2003), are of the same order of magnitude of estimated C emissions from US agriculture (see e.g., CAST 2004).

In another entry point to the carbon cycle, agriculture may help to mitigate anthropogenic greenhouse emissions through the production of bio-fuels. If available marginal land were used for energy crops, the IPCC projects significant displacement of fossil fuels, globally up to 3-4 GT $\mathrm{C} \mathrm{yr}^{-1}$ by mid century through conversion of $\sim 200 \mathrm{M}$ ha of marginal land to bio-fuel production (IPCC 2001c). However, issues of input availability, especially water, have not been considered in previous studies and need to be further investigated.

Because of the greater global warming potential (GWP) of $\mathrm{CH}_{4}$ (21) and $\mathrm{N}_{2} \mathrm{O}$ (310) compared to $\mathrm{CO}_{2}(1)$, mitigation of non- $\mathrm{CO}_{2}$ greenhouse gases in agriculture, can be quite significant and achieved via the development of more efficient rice (for methane) and livestock production systems (for both methane and nitrous-dioxide). In intensive agricultural systems with crops and livestock production, direct $\mathrm{CO}_{2}$ emissions are predominantly connected to field crop production and are typically in the range of 150$200 \mathrm{~kg} \mathrm{C} \mathrm{kg} \mathrm{C} \mathrm{ha}{ }^{-1} \mathrm{yr}^{-1}$ (e.g., West and Marland 2002; Flessa et al. 2002). Recent full greenhouse gas analyses of different farm systems in Europe showed that such $\mathrm{CO}_{2}$ emissions represent only $10-15 \%$ of the farm total, with methane contributing $25-30 \%$ and $\mathrm{N}_{2} \mathrm{O}$, by far the largest emitter, contributing roughly $60 \%$ of total greenhouse gas emissions from farm activities. The $\mathrm{N}_{2} \mathrm{O}$ contribution arises from substantial $\mathrm{N}$ volatilization from fertilized fields and animal waste, but it is also a consequence of its very high GWP.

In Europe, methane emissions are mostly linked to cattle digestive pathways; its contribution also dominates that of $\mathrm{CO}_{2}$, due in part to methane's high GWP. Mitigation measures for methane production in livestock include improved feed and nutrition regimes, as well as recovery of bio-gas for on-farm energy production. Strategies for effective mitigation of $\mathrm{N}_{2} \mathrm{O}$ emissions are far more difficult, given the largely heterogeneous nature of emissions in space and time and thus the difficulty of timing fertilizer applications and/ or manure management. Large uncertainties in emission factors also complicate the assessment of efficient $\mathrm{N}_{2} \mathrm{O}$-reduction strategies. Current techniques focus on reduction of absolute amounts of fertilizer $\mathrm{N}$ applied to fields, as well as on livestock feeding regimes that reduce animal excreta.

By analyzing all components of farm activities, Flessa et al. (2002) suggested that overall emissions of the non- $\mathrm{CO}_{2}$ gases could be reduced by about $25 \%$ by shifting to less intensive, organic production systems. Given the higher GWP of both $\mathrm{CH}_{4}$ and $\mathrm{N}_{2} \mathrm{O}$ compared to that of $\mathrm{CO}_{2}$ however, overall farm emissions could still be significant even in organic systems. A possibly viable strategy to mitigating non- $\mathrm{CO}_{2}$ gases in intensive mixed crop-livestock farming systems, such as those in place in both Europe and North America, 
might be a change in human diet towards less meat consumption, thus reducing livestock numbers, as well as grain production for feed (Flessa et al. 2002).

\subsection{Interactions of adaptation and mitigation strategies}

Agriculture plays a fundamental, dual role in human-driven climate change. On the one hand, it is one the key human sectors that will be affected by climate change over the coming decades, thus requiring adaptation measures. On the other, agriculture is also a major source of greenhouse gases to the atmosphere. As climate changes as well as socioeconomic pressures shape future demands for food, fiber and energy, synergies need to be identified between adaptation and mitigation strategies, so that robust options that meet both climate and societal challenges of the coming decades can be developed. Ultimately, farmers and others in the agricultural sector will be faced with the dual task of contributing to global reductions of carbon dioxide and other greenhouse gas emissions, while having to cope with an already changing climate.

First, one should consider interactions between adaptation strategies, which will certainly be implemented by farmers as climate changes, and the mitigation potential of the adapted system. Some very specific adaptation practices might not be conducive to mitigation at all. If, for example, agricultural zonation shifts the earth's potential agricultural limits polewards, increased cultivation in those previously marginal areas-certainly seen as a boon by certain countries, might on the other hand lead to substantial losses of SOC in previously undisturbed lands. The same might be true under major shifts in rotation systems with very different production levels, occurring across regions over large areas.

In terms of livestock production in intensive systems, warmer conditions in the coming decades might trigger the implementation of enhanced cooling and ventilation systems, or alternatively it may render necessary a reduction in stocking densities (Turnpenny et al. 2001). The former of such strategies would clearly counter on-farms mitigation efforts due to the associated increase in energy use, while the latter would greatly contribute to mitigation of non- $\mathrm{CO}_{2}$ greenhouse gases.

On the other hand, on the majority of current agricultural areas several adaptation practices may positively reinforce land mitigation potentials under specific conditions. For example, increased irrigation and fertilization necessary to maintain production in marginal semi-arid regions under climate change conditions, may also greatly enhance the ability of soils in those areas to sequester carbon. This would be especially true in subSaharan Africa, where small improvements in efficiency of irrigation can have very large effects on biomass production of crops (Solomon et al. 2000), and hence on their soil inputs. Under wet scenarios especially at mid-latitudes, a shift from fallow systems to continuous cultivation - an adaptation maximizing production under the new precipitation conditions-would also increase soil carbon sequestration potentials.

The interactions of mitigation potential with climate change itself need to be considered. Climate change impacts on agriculture will affect not only yields, but also SOC levels in agricultural soils. Such impacts can be either positive or negative, depending on the particular effect considered. Elevated $\mathrm{CO}_{2}$ alone will have positive effects on soil carbon storage, because increased above and belowground biomass production in the agro-ecosystem. Likewise, the lengthening of the growing season under warmer climates will allow for increased carbon inputs into soils. Warmer temperatures may also have negative effects on SOC however, by increasing decomposition rates as well as by reducing inputs by shortening crop life cycles. 
Increased variability and higher frequency of extreme events will negatively impact soil carbon storage, by both decreasing locally mean production levels, as well as by worsening soil quality in the areas affected. Paustian et al. (1998) simulated several cropping systems in the US Midwest under current and future projected climate, showing - in agreement with crop production assessment studies - both positive and negative results, varying regionally and as a function of climate scenarios used.

If changing climate is not taken into consideration, calculations of soil carbon sequestration potentials may be in serious error because of the interactions between climate and soil dynamics, As a result, mitigation strategies chosen today at given sites, without attention to likely changes in climate, may not produce the expected results.

For example, consider how climate change might modify the potential impacts of enhanced field input management for water and fertilizer N. By using a dynamic crop modeling system coupled to a soil carbon module (DSSAT; see for example Gijsman et al. 2002), we computed differences in SOC sequestration at a US Midwest site, following increased $\mathrm{N}$ and water application As shown in Fig. 4, while such mitigation strategies are projected to produce numbers that are consistent with those discussed in our section on mitigation, results may change substantially once climate change is taken into consideration. In our example, increased fertilization and/or irrigation management is projected to lead to additional SOC sequestration of about $0.1 \mathrm{~T} \mathrm{C} \mathrm{ha}^{-1} \mathrm{yr}^{-1}$ under current climate, in agreement with published estimates of mitigation potentials in agriculture. However, compared to the same baseline, climate change might entirely negate or sharply reduce such gains in the future. In addition, different climate scenarios will have different effects on final accumulation rates.

Interactions between mitigation strategies and adaptation measures may be important, although they are often overlooked. If the main avenue chosen for mitigation options related to soil carbon sequestration would be conversion of marginal agricultural lands to forestry, agro-forestry, grasslands, or bio-energy crops, competition for land and food would need to be considered as a function of specific socio-economic scenarios. Fischer et al. (2001) projected future extent of agricultural land as a function of SRES scenarios (IPCC 2000), showing a need for additional agricultural land on the order of 200$400 \mathrm{M}$ ha, mostly in Latin America and sub-Saharan Africa, under the scenario with the highest projected population and lower economic growth. Under the latter circumstances, very little additional marginal land would be available for mitigation purposes.

On current agricultural land however, interactions between mitigation and adaptation can be mutually re-enforcing, especially in view of increased climate variability under

Corn Field, North Platte, NE

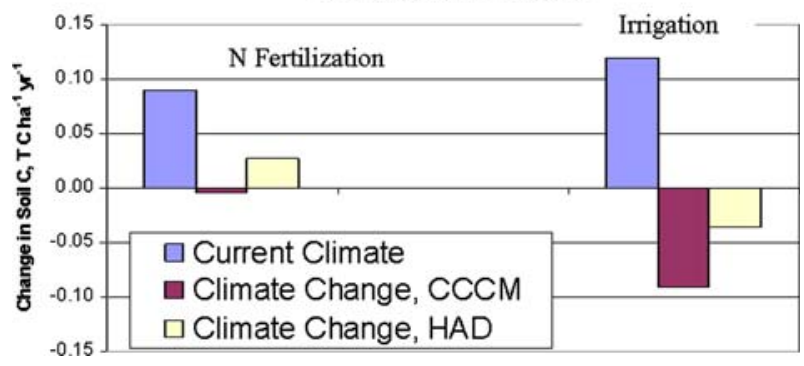

Fig. 4 Change in soil carbon in corn production under nitrogen fertilization and irrigation under current climate and under the Canadian Climate Centre, (CCCM) and Hadley Center (HAD) climate change scenarios. Simulated data provided by NASA-GISS climate impacts group 
climate change. This is because, most mitigation techniques currently considered in agriculture, including reduced tillage, were originally designed as "best practice'" management strategies, aimed at enhancing the long-term stability and resilience of cropping systems in the face of climate variability or of increased cultivation intensity. By increasing the ability of soils to hold soil moisture and to better withstand erosion, and by enriching ecosystem biodiversity through the establishment of more diversified cropping systems, many mitigation techniques implemented locally for soil carbon sequestration may also help cropping systems to better withstand droughts and/or floods, both of which are projected to increase in frequency and severity in future warmer climates.

\section{Research directions}

In order to better address the interactions between climate change, adaptation, mitigation, and sustainability of food and fiber production, we suggest the following areas for future research.

\subsection{Climate variability and change}

A bifurcation in the field of climate impacts has occurred between research on responses to major systems of climate variability, such the El Niño-Southern Oscillation, and responses to long-term global warming. The insights gained with regard to adaptation and mitigation on these two timescales-seasonal-to-interannual versus decadal-to-century-need to be reconciled. The work on seasonal-to-interannual climate forecasts has tended to focus on short-term decision-making following probabilistic predictions of climate extremes in connection with El Niño and La Niña events (Fig. 5). The role of local stakeholders is crucial at these shorter timescales, and responses are focused on adaptation. The work on the decadal-to-century timescale, on the other hand, has focused primarily on responses to mean changes and long-term decisions. The stakeholders for climate change impact studies have often been national policy-makers. The goal here has usually been to provide

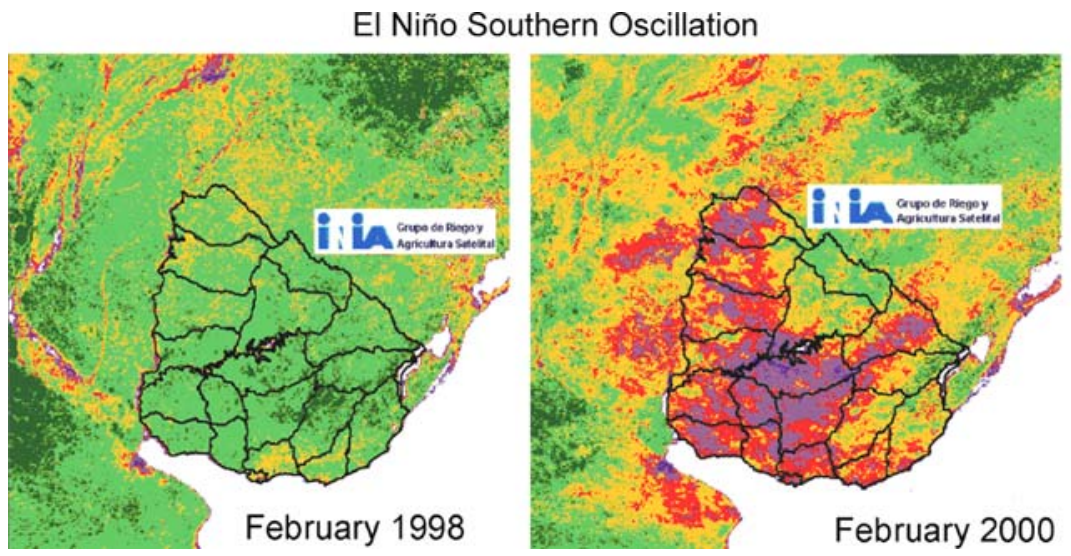

Fig. 5 Normalized vegetative index (NDVI) for Uruguay, showing wet periods during El Nino events (e.g., February 1998) and droughts during La Nina events (e.g., February 2000) 
information needed to help these decision-makers to devise long-term strategies in regard to the climate change issue, in terms of both mitigation and adaptation.

New theoretical constructs are needed to link climate-agriculture interactions on the two timescales, as well as new ways to utilize analytic tools such as dynamic crop growth models and statistical analyses. One need is to move beyond the readily tractable projections of crop responses to mean changes, towards the more difficult yet highly relevant issue of how crops may respond to altered climate variability, such as changes in the frequency and intensity of extreme events.

\subsection{Observed effects of warming trends}

Analyses of temperature records from around the world show that many regions are experiencing a warming trend, especially from the 1970s to the present. On average, warmer-than-normal springs have been documented in western North America since the late 1970s (Cayan et al. 2001). In some areas of the world, there have also been recent episodic increases in floods (e.g., North America) and droughts (e.g., the Sahel) (IPCC 2001a, b, c), with likely but as yet mostly undocumented effects on food production. The responses of agricultural systems to such changes need to be monitored and documented in regard to impacts and adaptation. Have farmers indeed switched to earlier planting dates? Have they changed cultivars? And are there any trends in yields that can be discerned in conjunction with the climate trends?

Such questions are difficult to answer because many other processes besides climate, including land-use change and agro-ecosystem degradation, have been occurring simultaneously. But such questions are important for furthering our understanding of agricultural adaptation to climate, and for validating the many simulation studies performed to date on potential climate change impacts over the coming decades. These analyses will contribute to the IPCC Fourth Assessment Report, now underway.

\subsection{Global and local scales}

An important bifurcation that needs to be resolved is the one between global and local/ regional scales. Recent work has emphasized the importance of scale in estimating the impacts of climate variability and change on agriculture (Mearns 2003). In order to understand how a changing climate will affect agriculture, we must find new ways to bring detailed knowledge on impacts and adaptation at local and regional scales to bear on global analyses.

Agriculture in any one region is linked to other agricultural regions, and indeed to the world food system, both through trade and through the food-donor system. As a changing climate shifts the comparative advantage of one region over another, additional regions will inevitably be affected. Thus, in research on agriculture and climate change, regional 'place-based' studies of vulnerability and adaptation, as well as mitigation, can contribute to a global synthesis.

\subsection{Mitigation and agriculture-forestry competition}

An emerging research area is related to the potential for competition between agriculture and forestry in regard to carbon-saving solutions. What are optimal strategies for land 
management leading to climate mitigation? For example, might carbon sequestration on agricultural land used for food production be 'out-competed' by biomass production for energy on the same fields? Might agro-forestry storage for carbon become more lucrative than cereal production? Several studies have started to analyze such interactions (e.g., Hyman et al. 2003; McCarl et al. 2001), including quantification of C-sequestration, secondary effects on impacts and the environment, and other pollutants such as tropospheric ozone (e.g., Rosenzweig et al. 1999; Feltzer et al. 2004). If a main avenue chosen for agricultural mitigation of greenhouse gas concentrations is conversion of marginal agricultural lands to forestry, agro-forestry, grasslands, or bio-energy crops, competition between these different carbon-sequestration techniques may ensue. Projections of land resources required for GHG mitigation and for food production need to be made as a function of specific socio-economic scenarios. These will be part of interdisciplinary studies that entrain agronomists, forestry scientists, and economists in order to develop full carbon and food accounting for agricultural systems over sufficiently long time periods in the future to capture the complex interactions among these processes.

\section{Conclusions}

Climate change and variability will affect agricultural systems substantially, requiring farmers to adapt at the same time that they are called on to reduce emissions at the farm level. Choosing effective adaptation and mitigation strategies will represent a key challenge for farmers over the coming decades. Optimal strategies are those that, via careful management of land, maintain or increase the resilience and stability of production systems, while also sequestering soil carbon and/or reducing fluxes from farm activities. Although many positive interactions have been identified in this essay, it is important to note that synergies will not be possible under all climate and socio-economic scenarios, and across regions. Adaptation strategies will likely often take precedence over mitigation, as climate changes are already under way and farmers will adapt (as they have always done), in order to maintain production systems and thus their own incomes and livelihoods. Certainly, over the coming decades, the global and regional challenges connected to anthropogenic climate forcing call for the need to maximize collaboration among scientists, farmers and land managers, politicians, and citizens, in order to ensure efficient responses to a global problem that is in essence interconnected across years, regions, and societal sectors.

Finally, improving responses to climate variability and change is a crucial requirement for future agricultural sustainability. The challenge for the field of climate change impacts on agriculture, including the design of appropriate adaptation and mitigation solutions, is to integrate insights from the physical, biophysical, and social sciences into a comprehensive understanding of climate-agriculture interactions at seasonal-to-interannual and decadal-tocentury timescales, as well as at regional and global spatial scales. The ultimate challenge is to apply this knowledge to 'real-world' agricultural practices and planning worldwide, so that long-term sustainability may be effectively enhanced under climate change, by finding the optimal synergies between the necessary adaptation and mitigation strategies.

Acknowledgements We wish to thank three anonymous reviewers for their constructive comments, which helped us to improve the overall structure and clarity of the manuscript. The research was supported in part by a grant of the Italian Ministry of the Environmentadministered by INGV Bologna. F. N. Tubiello was supported in part by NOAA grant GC02-333. 


\section{References}

Acock B, Allen LH Jr (1985) Crop responses to elevated carbon dioxide concentrations. In: Strain BR, Cure JD (eds) Direct effects of increasing carbon dioxide on vegetation. DOE/ERB0238. U.S. Department of Energy, Washington DC, pp 53-97

Adams RM, McCarl BA, Segerson K, Rosenzweig C, Bryant KJ, Dixon BL, Connor R, Evenson RE, Ojima D (1999) The economic effects of climate change on US agriculture. In: Mendelsohn R, Neumann JE (eds) Impact of climate change on the United States economy. Cambridge University Press

Bongaarts J (1994) Can the growing human population feed itself? Sci Am 270(3):18-24

CAST Council for Agricultural Science and Technology (2004) Climate change and greenhouse gas mitigation: challenges and opportunities for agriculture. Task Force Report, p 133

Cayan DR, Kammerdiener SA, Dettinger MD et al (2001) Changes in the onset of spring in the western United States. B Am Meteorol Soc 8(3):399-415

Chen C-C, McCarl BA (2001) An investigation of the relationship between pesticide usage and climate change. Clim Change 50:475-487

Chmielewski FM, Muller A, Bruns E (2004) Climate changes and trends in phenology of fruit trees and field crops in Germany, 1961-2000. Agricult For Meteorol 121(1-2):69-78

Coakley SM, Scherm H, Chakraborty S (1999) Climate change and plant disease management. Ann Rev Phytopathol 37:399-426

Cure JD, Acock B (1986) Crop responses to carbon dioxide doubling: a literature survey. Agricult For Meteorol 38:127-145

Dahlsten DL, Garcia R (eds) (1989) Eradication of exotic pests: analysis with case histories. Yale University Press, New Haven Connecticut

Easterling WE, Crosson PR, Rosenberg NJ, McKenney MS, Katz LA, Lemon KM (1993) Agricultural impacts of and responses to climate change in the Missouri-Iowa-Nebraska-Kansas (MINK) region. Clim Change 24:23-61

Felzer B, Reilly J, Melillo J, Kicklighter D, Wang C, Prinn R, Sarofim M, Zhuang Q (2004) Past and future effects of ozone on net primary production and carbon sequestration using a global biogeochemical model. http://web.mit.edu/globalchange/www/reports.html\#pubs. Clim Change (in press)

Fischer G, Shah M, Velthuizen H, Nachtergael FO (2001) Global agro-ecological assessment for agriculture in the 21st century. International Institute for Applies Systems Analysis. IIASA Publications, Vienna Austria

Flessa H, Ruser R, Dörsch, Kamp PT, Jimenez MA,Munch JC, Beese F (2002) Integrated evaluation of greenhouse gas emissions $\left(\mathrm{CO}_{2}, \mathrm{CH}_{4}, \mathrm{~N}_{2} \mathrm{O}\right)$ from two farming systems in southern Germany. Agric Ecosys Environ 91:175-189

Gijsman AJ, Hoogenboom G, Parton WJ, Kerridge PC (2002) Modifying DSSAT for low-input agricultural systems, using a soil organic matter residue module from CENTURY. Agron J 94(3):462-474

Hendrey GR, Lewin KF, Nagy J (1993) Free air carbon dioxide enrichment: development, progress, results. Vegetation 104:17-31

Hitz S, Smith J (2004) Estimating global impacts of climate change. Glob Environ Ch 14:201-218

Hsiao TC, Jackson RB (1999) Interactive effects of water stress and elevated $\mathrm{CO}_{2}$ on growth, photosynthesis, and water use efficiency. In: Luo Y, Mooney HA (eds) Carbon dioxide and environmental stress. Academic Press, New York, pp 3-31

Hyman RC, Reilly JM, Babiker MH, De Masin A, Jacoby HD (2003) Modeling non- $\mathrm{CO}_{2}$ greenhouse gas abatement. Environ Mod Assess 8(3):175-186

IPCC (2001a) Climate change 2001:the scientific assessment. Intergovernmental Panel on Climate Change. Cambridge University Press, Cambridge UK, 845 pp

IPCC (2001b) Climate change 2001: impacts, adaptation, and vulnerability. Intergovernmental Panel on Climate Change. Cambridge University Press. Cambridge, UK, 1032 pp

IPCC (2001c) Climate change 2001: mitigation. Intergovernmental Panel on Climate Change. Cambridge University Press. Cambridge, UK, 1076 pp

IPCC (1996) Watson RT, Zinyowera MC, Moss RH (eds) Climate change 1995: impacts, adaptations and mitigation of climate change: Scientific-Technical Analyses. Chaps. 13 and 23. The Intergovernmental Panel on Climate Change second assessment Report, vol. 2. Cambridge University Press, Cambridge $\mathrm{UK}, 878 \mathrm{pp}$

IPCC (2000) Special Report on Emissions Scenarios (SRES) Nakićenović N, Alcamo J, Davis G, de Vries B, Fenhann J, Gaffin S, Gregory K, Grübler A et al (eds) Working group III, Intergovernmental Panel on Climate Change. Cambridge University Press, Cambridge, 595 pp

Kimball BA (1983) Carbon dioxide and agricultural yield: an assemblage and analysis of 430 prior observations. Agron J 75:779-788 
Kimball BA, Idso SB (1983) Increasing atmospheric $\mathrm{CO}_{2}$. Effects on crop yield, water use and climate. Agric Water Manage 7:55-72

Kimball BA, Kobayashi K, Bindi M (2002) Responses of agricultural crops to free-air CO2 enrichment. Adv Agron 77: 293-368

Lal R, Follett RF, Kimble J, Cole CV (1999) Managing US cropland to sequester carbon in soil. J Soil Water Conserv 54:374-381

Lincoln DE, Sionit N, Strain BR (1984) Growth and feeding response of Pseudoplusia includens (Lepidoptera: Noctuidae) to host plants grown in controlled carbon dioxide atmospheres. Environ Entomol $13: 1527-1530$

LULUCF (2000) IPCC special reports: land use, land-use change, and forestry. Watson RT, Noble IR, Bolin B, Ravindranath NH, Verardo DJ, Dokken DJ (eds) (2000) Cambridge University Press, Cambridge, $324 \mathrm{pp}$

McCarl BA, Schneider UA (2001) Greenhouse gas nitigation in US. Agric For Sci 294:2481-2482

Mearns LO (ed) (2003) Issues in the impacts of climate variability and change on agriculture: applications to the southeastern United States. Kluwer Academic Publishers, Dordrecht, 216 pp

Mendelsohn R, Nordhaus W, Shaw D (1994) The impact of climate on agriculture: a Ricardian approach. Amer Econ Rev 84:753-771

Milly PCD, Wetherald RT, Dunne KA, Delworth TL (2002) Increasing risk of great floods in a changing climate. Nature 415:514-517

Nicholls N (1997) Increased Australian wheat yields due to recent climate trends. Nature 387:484-485

Parry ML, Rosenzweig C, Iglesias A, Livermore M, Fischer G (2004) Effects of climate change on global food production under SRES emissions and socio-economic scenarios. Global Environ Chang 14:5367

Patterson DT (1993) Implications of global climate change for impact of weeds insects, and plant diseases. In: International Crop Science I. Crop Science Society of America, Madison, Wisconsin, pp 273-280

Paustian K, Elliot ET, Killian K (1998) Modeling soil carbon in relation to management and climate change in some agro-ecosystems in central North America. In: Lal R et al (eds) Soil processes and the carbon cycle. CRC Press, Boca Raton FL, pp 459-471

Peng S, Huang J, Sheehy JE et al (2004) Rice yields decline with higher nighttime temperature from global warming. Proceedings of the National Academy of Sciences

Polsky C (2004) Putting space and time in ricardian climate change Impact Studies: the case of agriculture in the U.S. great plains. Annals of the Association of American Geographers 94(3):549-564

Poorter $\mathrm{H}$ (1993) Interspecific variation in the growth response of plants to an elevated ambient $\mathrm{CO}_{2}$ concentration. Vegetation 104/105:77-97

Reilly J, Tubiello F, McCarl B, Abler D, Darwin R, Fuglie K, Hollinger S, Izaurralde C, Jagtap S, Jones J, Mearns L, Ojima D, Paul E, Paustian K, Riha S, Rosenberg N, Rosenzweig C (2003) US Agriculture and climate change: new results. Clim Change 57:43-69

Rosenzweig C, Iglesias A, Fischer G, Liu Y, Baethgen W, Jones JW (1999) Wheat yield functions for analysis of land-use change in China. Environ Model Assess 4:15-132

Rosenzweig C, Hillel D (1998) Climate change and the global harvest: potential impacts of the greenhouse effect on agriculture. Oxford University Press, New York, NY, 324 pp

Rosenzweig C, Parry ML (1994) Potential impacts of climate change on world food supply. Nature 367:133-138

Rosenzweig C, Iglesias A, Yang XB, Epstein PR, Chivian E (2002a) Climate change and extreme weather events: implications for food production, plant diseases, and pests. Global Change Human Health 2(2):90-104

Rosenzweig C, Tubiello FN, Goldberg R, Mills E, Bloomfield J (2002b) Increased crop damage in the US from excess precipitation under climate change. Global Environ Change 12:197-202

Rosenzweig C, Ritchie JT, Jones JW, Tsuji GY, Hildebrand P (1995) Climate change and agriculture: analysis of potential international impacts. ASA Spec. Publ. No. 59, American Society of Agronomy, Madison WI, $382 \mathrm{pp}$

Rosenzweig C, Strzepek KM, Major DC, Iglesias A, Yates DN, McCluskey A, Hillel D (2004) Water resources for agriculture in a changing climate: international case studies. Global Environ Change $14: 345-360$

Root TL, Price JT, Hall KR, Schneider SH, Rosenzweig C, Pounds JA (2003) Fingerprints of global warming on wild animals and plants. Nature 421:57-60

Salt DT, Brooks BL, Whitaker JB (1995) Elevated carbon dioxide affects leaf-miner performance and plant growth in docks (Rumex spp.). Global Change Biol 1:153-156

Schlesinger WH (1999) Carbon sequestration in soils. Science 284:2095 
Smit B, Skinner MW (2002) Adaptation options in agriculture to climate change: a typology. Mit Adapt Strategies Glob Ch 7:85-114

Smith JB, Klein RJT, Huq S (2003) Climate change, adaptive capacity, and development. Imperial College Press, London, 347 pp

Solomon D, Lehmann J, Zech W (2000) Land use effects of soil organic matter properties of chromic luvisols in semi-arid northern Tanzania: carbon, nitrogen, lignin and carbohydrates. Agr Ecos Env 78:203-213

Sperow M, Eve M, Paustian K (2003) Potential soil C sequestration on US agricultural soils. Clim Change 57:319-339

Sutherst RW (1990) Impact of climate change on pests and diseases in Australia. Search 21:230-232

Tubiello FN, Ewert F (2002) Modeling the effects of elevated $\mathrm{CO}_{2}$ on crop growth and yield: a review. Eur J Agron 18(1-2):57-74

Tubiello FN, Jagtap S, Rosenzweig C, Goldberg R, Jones JW (2002) Effects of climate change on US crop production from the National Assessment. Simulation results using two different GCM scenarios. Part I: Wheat, Potato, Corn, and Citrus, Climate Res 20(3):259-270

Turnpenny JR, Parsons DJ, Armstrong AC, Clark JA, Cooper K, Matthews AM (2001) Integrated models of livestock systems for climate change studies. 2. Intensive systems. Global Change Biol 7:163-170

West TO, Marland G (2002) A synthesis of carbon sequestration, carbon emissions, and net carbon flux in agriculture: comparing tillage practices in the United States. Agr Ecosys Environ 91:217-232 